\title{
Kriteria Mutu Kopi Arabika Gayo pada Beberapa Koperasi dan Eksportir di Aceh Tengah
}

\author{
(Quality Criteria for Gayo Arabica Coffee in Several Cooperatives and Exporters in Central \\ Aceh)
}

\author{
Abdul Kudus, Heru Prono Widayat ${ }^{1}$, Yusya Abubakar ${ }^{1 *}$ \\ ${ }^{1}$ Program Studi Teknologi Hasil Pertanian, Fakultas Pertanian, Universitas Syiah Kuala
}

\begin{abstract}
Abstrak. Salah satu komoditi ekspor unggulan Indonesia yang telah dikenal dipasar domestik dan Internasional adalah Kopi Arabika Gayo (Arabica Coffee). Tujuan dari penelitian ini adalah mengetahui kriteria mutu penerimaan kopi arabika Gayo pada beberapa koperasi dan eksportir di Aceh Tengah. Ada dua koperasi dan dua eksportir di Kabupaten Aceh Tengah, yang dijadikan sebagai responden, yaitu eksportir A dan B, serta koperasi A dan B. Pengumpulan data dilakukan dengan observasi, wawancara, dan dokumentasi, secara langsung maupun melalui kuesioner. Data hasil wawancara dan kuisioner disajikan dalam bentuk tabel. Syarat mutu yang menjadi acuan oleh koperasi dan eksportir adalah SNI No. 01-2907-2008 tentang Syarat Mutu Biji Kopi. Setiap koperasi dan eksportir membeli kopi biji dari anggota/petani dengan syarat-syarat kualitas tertentu. Kriteria penerimaan kopi gelondong, kopi gabah, kopi beras, yang dugunakan oleh responden cukup beragam dan ada yang belum sepenuhnya mengikuti standar SCAA dan SNI. Namun kriteria mutu yang mereka gunakan ketika menjual/ekspor kopi harus sesua dengan SNI dan SCAA.
\end{abstract}

Keywords: eksportir, koperasi, kopi, mutu.

\begin{abstract}
One of the leading export commodities in Indonesia that has been known in the domestic and international markets is Gayo Arabica Coffee (Arabica Coffee). The purpose of this study was to determine the quality criteria for receiving Gayo arabica coffee in several cooperatives and exporters in Central Aceh. In this study, there were two cooperatives and two exporters (Central Aceh District), which were made as respondents, namely exporters A, B, cooperatives A, B. Data collection was done by observation, interviews, and documentation, directly or through questionnaires. Data from interviews and questionnaires were presented in the form of tables for the purpose of analyzing coffee criteria, which were used by cooperatives and exporters. Quality requirements that become a reference by cooperatives and exporters are SNI No. 01-2907-2008 concerning the Quality Requirements of Coffee Beans. Every cooperative and exporter bought seeds from members/farmers with certain quality conditions. The criteria for receiving coffee beans, grain coffee, rice coffee which were used by respondents were quite diverse and some did not fully followed the standards of SCAA and SNI. However, the quality criteria used when selling / exporting coffee must be in accordance with SNI and SCAA.
\end{abstract}

Keywords: exporters, cooperatives, coffee, quality.

\section{PENDAHULUAN}

Salah satu komoditi ekspor unggulan di Indonesia yang telah dikenal dipasar domestik dan Internasional adalah Kopi Arabika Gayo (Arabica Coffee). Jenis kopi yang umum dibudidayakan di Dataran Tinggi Gayo adalah kopi Arabika. Kopi Arabika sangat cocok untuk tumbuh di wilayah ini yang didominasi ketinggian tempat $900-1700 \mathrm{~m}$ dpl yang merupakan tempat yang ideal untuk budidaya kopi Arabika. Permintaan terhadap kopi arabika (Coffea arabica L.) Indonesia dari waktu ke waktu terus meningkat. Kopi arabika yang dihasilkan oleh berbagai daerah di Indonesia mempunyai karakteristik cita rasa (acidity, aroma, flavour) yang unik. Dari total produksi tahun ini sekitar 660.000 - 690.000 ton. Ekspor kopi pun akan mencapai sekitar 420.000 ton di mana 330.000 ton merupakan kontribusi dari ekspor kopi robusta (AEKI, 2011). 
Kondisi yang terjadi di lapangan, di sentra produksi kopi Arabika tidak semua petani melakukan kegiatan teknis yang sudah disarankan untuk memenuhi standar mutu kopi. Pada saat pemanenan buah, ada yang memetik campuran antara buah hijau dan merah, dan ada juga yang memetik buah yang merah saja. Pada saat melakukan penjemuran biji kopi, ada petani yang menjemur langsung diatas badan jalan, ada yang memakai alas atau terpal penjemuran, dan ada juga yang memakai lantai jemur. Kasus di daerah Kute Panang, setelah memetik buah merah, petani langsung menjualnya kepada pengumpul. Di Kecamatan Jagong Jeget, terdapat petani yang menjual buah kopi merah hingga gabah, di sisi lain di Kecamatan Atu Lintang dan Bebesen, petani menjual kopi gabah (parchment coffee) dan sedikit yang menjual kopi beras (green beans). Oleh karena itu peran koperasi dan pengumpul menjadi sangat penting dalam mempertahankan kualitas kopi (ICO, 2012).

Pelaku utama dalam perdagangan kopi di Aceh Tengah adalah koperasi dan eksportir (perusahaan). Koperasi merupakan badan hukum yang berdasarkan atas asas kekeluargaan yang anggotanya terdiri atas beberapa orang ataupun badan hukum yang bertujuan mensejahterakan masyarakat ataupun anggota koperasi. Pada umumnya koperasi dikendalikan secara bersama oleh seluruh anggotanya. Setiap anggota memiliki hak suara yang sama dalam setiap keputusan yang diambil oleh koperasi. Pembagian keuntungan koperasi biasa disebut sisa hasil usaha (SHU) yang dihitung secara adil. Disaat kondisi bangsa yang dilanda kesulitan ekonomi, koperasi merupakan salah satu lembaga petani dan lembaga keuangan yang sejajar dengan lembaga lain yang telah ada pada masa ini. Agar dapat bertahan dan bersaing dengan lembaga yang lainnya, maka koperasi harus dapat mempertahankan kesejahteraan masyarakat (Arfah, 1993). Adapun eksportir merupakan orang atau lembaga perantara dagang yang melakukan kegiatan pengiriman barang ke negara lain yang membutuhkan. Dari kegiatan yang dilakukan berharap Eksportir ini bisa merubah produksi ekspor keluar negeri.

Dari informasi yang didapat, koperasi dan eksportir kopi Arabika Gayo menetapkan kriteria penerimaan kopi dari pemasok (petani, kelompok tani, pedagang pengumpul) yang berbeda-beda. Penelitian ini bertujuan untuk menganalisis kriteria penerimaan yang diterapkan oleh koperasi/eksportir di Kabupaten Aceh Tengah dalam menerima/ membeli kopi dan membandingkan dengan standar yang sudah ada.

\section{METODE PENELITIAN}

Dalam penelitian ini memiliki tahapan pengumpulan data dilapangan diantaranya penyiapan kuisioner penelitian, observasi, wawancara dan dokumentasi. Penelitian ini dilaksanakan di Kabupaten Aceh Tengah, dengan objek empat perusahaan koperasi dan eksportir. Penelitian tersebut dilaksanakan pada bulan Maret sampai April tahun 2018.

\section{Alat dan Bahan}

Alat yang di gunakan dalam penelitian ini adalah, kamera, kuisioner, alat bantu tulis, dan perangkat komputer. Sedangkan, Bahan yang digunakan dalam penelitian ini berbentuk data atau informasi yang diperoleh dari 2 koperasi dan 2 eksportir kopi di Aceh Tengah.

\section{Prosedur Penelitian}

Prosedur penelitian meliputi survey untuk menentukan populasi dan sampel penelitian, persiapan kuisioner, observasi dan dokumentasi terhadap sampel eksportir dan koperasi yang

Kriteria Mutu Kopi Arabika pada Beberapa Koperasi dan Eksportir di Aceh Tengah. (Abdul Kudus, Heru Prono Widayat, Yusya' Abubakar) 
menjadi sampel. Sampel terdiri atas 2 koperasi dan eksportir. Kuisioner untuk observasi dan wawancara meliputi kriteria penerimaan kopi gelondong, kopi gabah dan kopi beras. Data hasil analisis disesuaikan dengan syarat mutu kopi menurut SNI.

\section{Analisis Data}

Analisis data yang dilakukan menggunakan Microsoft excel dalam bentuk tabel untuk tujuan evaluasi mutu kopi dalam sistem koperasi dan eksportir. Data dianalisis secara deskriptif.

\section{HASIL DAN PEMBAHASAN}

\section{Gambaran Usaha Tani Kopi Arabika Gayo}

Nilai ekspor kopi gayo mengalami peningkatan tajam selama periode 2017. Kopi asal Aceh tersebut, naik 200\% jika dibandingkan pada 2016. Tahun 2017, nilai ekspor komoditi kopi Aceh tembus angka USD34,41 juta lebih tinggi dibandingkan periode sama pada 2016 yang hanya mencapai USD11,46 juta. Banyaknya volume kopi yang dipasarkan ke pasar dunia menunjukkan bahwa eksportir memiliki peran strategis dalam pasar kopi Arabika Gayo. Sebagian besar kopi di dataran tinggi gayo diproduksi oleh petani (surip, M. 2008).

Peran petani sangat besar dalam menjaga kualitas kopi Gayo. Petani kopi rata-rata mempunyai 1-2 Ha kebun kopi dengan membayar tenaga pemetik pada saat dilakukan pemanenan kopi. Umumnya petani menjual kopi merah, namun ada juga yang menjual gabah, dan hanya sedikit yang menjual kopi biji. Rata-rata yang membeli buah merah adalah pedagang pengumpul ataupun kolektor. Ada empat koprasi/eksportir yang turut berperan dalam menentukan nilai dari total ketersediaan kopi Arabika Gayo di Provinsi Aceh, yaitu eksportir A, eksportir B, koperasi A, koprasi B. Setiap koperasi dan eksportir akan membeli dari anggota/petani dengan syarat-syarat tertentu (Siregar, 2012).

Dipasar kopi dunia, kopi Arabika Gayo tergolong kopi spesialti yang telah memiliki sertifikasi produk. Oleh karenanya, pada tahun 2012 harga jual kopi Arabika Gayo meningkat sampai 20\% (Rp 78.510) lebih tinggi dibandingkan harga kopi Arabika dunia (Rp 65.400) di pasar New York (AEKI, 2013). Namun, tingginya harga jual kopi Arabika Gayo belum dinikmati oleh petani. Kondisi ini dapat terlihat dari pengaruh struktur dan integrasi pasar kopi Arabika Gayo di Kabupaten Aceh Tengah, Bener Meriah dan Gayo Lues.

\section{Kriteria Penerimaan Kopi Gelondong}

Kopi gelondong merupakan buah kopi yang masih utuh yang belum terpisah dari daging buah beserta kulitnya. Umumnya eksportir A, eksportir B ,koperasi A dan koperasi B tidak membeli buah kopi mentah/kopi gelondong dan petani maupun pengumpul.

\section{Kriteria Penerimaan Kopi Gabah}

Kopi gabah merupakan kopi yang telah dipisahkan dari daging buah dan kulitnya, yang sudah dikeringkan. Umumnya koperasi dan eksportir rmembeli kopi gabah yang diproduksi oleh masyarakat. Namun dari hasil observasi di ketahui bahwanya eksportir A, eksportir B, dan koperasi A yang membeli kopi gabah, sedangkan koperasi B tidak membeli kopi gabah. Eksportir A, eksportir B, dan koperasi A masing-masing menentukan kriteria pada saat membeli kopi gabah. Yaitu kadar air, jumlah cacat, rendemen, penampakan gabah, 
(penampakan visual) dan kualitas yang bagus. Dengan dilakukan pengecekan tersebut eksportir dan koperasi dapat mengetahui kopi yang akan dibeli berkualitas atau tidak.

Tabel 1. Kriteria penerimaan kopi gabah oleh koperasi dan eksportir di Aceh Tengah

\begin{tabular}{|c|c|c|c|c|}
\hline Uraian & Eksportir A & Eksportir B & Koperasi A & Koperasi B \\
\hline $\begin{array}{l}\text { Kreteria yang ditentukan } \\
\text { oleh koperasi/ eksportir saat } \\
\text { membeli kopigabah }\end{array}$ & $\begin{array}{l}\text {-Kadar air } \\
\text {-Jumlah cacat } \\
\text {-rendemen } \\
\text { - penampakan } \\
\text { gabah } \\
\text {-penampakan } \\
\text { visual }\end{array}$ & $\begin{array}{l}\text {-Kadar air } \\
\text {-Jumlah cacat } \\
\text {-rendemen } \\
\text { - penampakan } \\
\text { gabah } \\
\text {-penampakan } \\
\text { visual }\end{array}$ & $\begin{array}{l}\text {-Kadar air } \\
\text {-Jumlah cacat } \\
\text {-Rendemen } \\
\text { - Penampakan } \\
\text { gabah } \\
\text {-penampakan visual }\end{array}$ & $\begin{array}{l}\text { Tidak } \\
\text { membeli kopi } \\
\text { gabah }\end{array}$ \\
\hline $\begin{array}{l}\text { Koperasi/ eksportir ini } \\
\text { mengklasifikasikan kopi } \\
\text { gabah }\end{array}$ & $\begin{array}{l}\text { berdasarkan } \\
\text { rendemen kopi }\end{array}$ & $\begin{array}{l}\text { berdasarkan } \\
\text { rendemen kopi }\end{array}$ & $\begin{array}{l}\text { timbangan kalau } \\
\text { bagus naik } 12 \text { on } \\
\text { perbambu }\end{array}$ & \\
\hline $\begin{array}{l}\text { Kreteria utama kopi gabah } \\
\text { yang bermutu tinggi }\end{array}$ & $\begin{array}{l}\text { Rendemen biji } \\
\text { minimal } 60 \%\end{array}$ & $\begin{array}{l}\text { Rendemen biji } \\
\text { minimal } 60 \%\end{array}$ & $\begin{array}{l}\text { rendemen biji } \\
\text { minimal } 65 \%\end{array}$ & \\
\hline $\begin{array}{l}\text { Kadar air gabah kopi yang } \\
\text { dapat diterima oleh } \\
\text { koperasi/eksportir }\end{array}$ & $30 \%-50 \%$ & $30-50 \%$ & $40 \%-50 \%$ & \\
\hline $\begin{array}{l}\text { Kadar air gabah kopi yang } \\
\text { ditolak oleh } \\
\text { koperasi/eksportir saat } \\
\text { pembelian kopi gabah }\end{array}$ & di atas $50 \%$ & diatas $50 \%$ & diatas $60 \%$ & \\
\hline $\begin{array}{l}\text { SNI menjadi salah satu } \\
\text { panduan dalam menentukan } \\
\text { mutu kopi gabah }\end{array}$ & SCAA & SCAA & SNI & \\
\hline $\begin{array}{l}\text { Kopi gabah yang ditolak saat } \\
\text { pembelian karena tidak } \\
\text { sesuai kreteria }\end{array}$ & $\begin{array}{l}\text {-karena } \\
\text { rendemen } \\
\text {-cacat kopi } \\
\text { terlalu tinggi }\end{array}$ & $\begin{array}{l}\text {-karena rendemen } \\
\text {-cacat terlalu } \\
\text { tinggi }\end{array}$ & $\begin{array}{l}\text {-karena rendemen } \\
\text { - jumlah cacat kopi } \\
\text { terlalu tinggi }\end{array}$ & \\
\hline Harga kopi gabah perbambu & $30-40$ ribu & $30-40$ ribu & 40 ribu & \\
\hline $\begin{array}{l}\text { Yang dipertimbangkan } \\
\text { koperasi/ perusahaan ini } \\
\text { dalam menentukan harga } \\
\text { kopi gabah }\end{array}$ & $\begin{array}{l}\text { Mutu kopi gabah } \\
\text { yang di hasilkan }\end{array}$ & $\begin{array}{l}\text { Mutu kopi gabah } \\
\text { yang di hasilkan }\end{array}$ & $\begin{array}{l}\text { tergantung kontrak } \\
\text { dengan penjual kopi }\end{array}$ & \\
\hline
\end{tabular}

\section{Kriteria Penerimaan Kopi Beras}

Kopi beras merupakan biji kopi kering yang sudah dibuang kulit tanduk dan kulit arinya. Eksportir A, eksportir B dan koperasi B umumnya membeli kopi beras yang di bawa ke koperasi/eksportir tersebut, sedangkan koprasi A tidak membeli kopi beras. Kriteria kopi beras yang disaratkan oleh ekportir A, eksportir B dan koperasi B yaitu kopi beras dengan nilai kadar air $15 \%$ dan cacat sekitar $15 \%$.

Kriteria Mutu Kopi Arabika pada Beberapa Koperasi dan Eksportir di Aceh Tengah. (Abdul Kudus, Heru Prono Widayat, Yusya' Abubakar) 
Tabel 2. Kriteria penerimaan kopi beras di Aceh Tengah oleh koprasi dan eksportir
Uraian
Ekportir A
Eksportir B
Koperasi A
Koperasi B

\begin{tabular}{|c|c|c|c|}
\hline $\begin{array}{l}\text { Kadar air kopi beras yang } \\
\text { diterima }\end{array}$ & $15 \%$ & $15 \%$ & $15 \%$ \\
\hline $\begin{array}{l}\text { Alat yang digunakan untuk } \\
\text { mengetahui kadar air }\end{array}$ & $\begin{array}{l}\text { sierra moisture } \\
\text { tester }\end{array}$ & $\begin{array}{l}\text { sierra moisture } \\
\text { tester }\end{array}$ & sierra moisture tester \\
\hline $\begin{array}{l}\text { Kreteria yang disaratkan } \\
\text { oleh koperasi/ eksportir ini } \\
\text { dalam membeli kopi beras }\end{array}$ & $\begin{array}{l}\text {-kadar air } 15 \% \\
\text { - cacat } 15 \%\end{array}$ & $\begin{array}{l}\text {-kadar air } 15 \% \\
\text { - cacat } 15 \%\end{array}$ & $\begin{array}{l}\text {-Kadar air } 15 \% \\
\text { - defects } 15 \%\end{array}$ \\
\hline $\begin{array}{l}\text { Petugas koperasi/eksportir } \\
\text { untuk membeli kopi } \\
\text { biji/kopi labu di desa dan } \\
\text { kecamatan }\end{array}$ & 25 orang & 28 orang & $\begin{array}{l}\text { setiap desa di bawah } \\
\text { binaan koperasi }\end{array}$ \\
\hline $\begin{array}{l}\text { Cara menentukan mutu kopi } \\
\text { beras yang akan dibeli }\end{array}$ & $\begin{array}{l}\text {-triage } \\
\text {-kadar air } \\
\text {-kopi kering }\end{array}$ & $\begin{array}{l}\text {-triage } \\
\text {-kadar air } \\
\text {-kopi kering }\end{array}$ & Cup test \\
\hline $\begin{array}{l}\text { Mutu fisik merupakan hal } \\
\text { yang paling utama } \\
\text { dipertimbangkan sebelum } \\
\text { membeli kopi beras }\end{array}$ & $\begin{array}{l}\text {-Bukan } \\
\text {-yang utama } \\
\text { rasa kopi }\end{array}$ & $\begin{array}{l}\text {-Tidak } \\
\text {-yang utama cita } \\
\text { rasa kopi }\end{array}$ & $\begin{array}{l}\text {-tidak } \\
\text {-yang utama cita rasa } \\
\text { kopi }\end{array}$ \\
\hline $\begin{array}{l}\text { Pengujian mutu cita rasa } \\
\text { sebelum membeli kopi beras }\end{array}$ & Ya & ya & Wajib \\
\hline $\begin{array}{l}\text { Pemeriksaan biji cacat saat } \\
\text { pembelian kopi beras }\end{array}$ & Ya & Ya & Ya \\
\hline Harga kopi berasperkilo & 74 ribu & $\begin{array}{l}74 \text { ribu tergantung } \\
\text { banyaknya panen }\end{array}$ & $\begin{array}{l}74 \text { ribu tergantung } \\
\text { nilai kontrak }\end{array}$ \\
\hline $\begin{array}{l}\text { Banyak (jumlah) kopi biji } \\
\text { yang ditolak karena tidak } \\
\text { memenuhi kreteria }\end{array}$ & $10 \%$ & $10 \%-15 \%$ & Di bawah 5\% \\
\hline $\begin{array}{l}\text { a. Penjemuran setelah } \\
\text { membeli kopi beras }\end{array}$ & $\begin{array}{l}\text { Ada tergantung } \\
\text { kadar air }\end{array}$ & -ada tergantung & dijemur lagi \\
\hline $\begin{array}{l}\text { b.Rata-rata jumlah hari } \\
\text { penjemuran }\end{array}$ & $\begin{array}{l}\text {-gabah } 3 \text { hari - } \\
\text { beras } 1 \text { hari }\end{array}$ & $\begin{array}{l}\text {-gabah } 4 \text { hari } \\
\text { - beras } 2 \text { hari }\end{array}$ & Sampai kadar air $12 \%$ \\
\hline $\begin{array}{l}\text { Kopi dijemur di atas lantai } \\
\text { jemur atau di atas terpal }\end{array}$ & Terpal & Terpal & Terpal \\
\hline $\begin{array}{l}\text { Pemeriksaan kadar air biji } \\
\text { kopi sebelum penggudangan }\end{array}$ & Ya & Ya & $\begin{array}{l}\text { ya menggunakan } \\
\text { tester }\end{array}$ \\
\hline $\begin{array}{l}\text { Penggudangan sebelum kopi } \\
\text { beras di jual ada }\end{array}$ & Ya & $\mathrm{Ya}$ & Ya \\
\hline $\begin{array}{l}\text { Uji cita rasa sebelum } \\
\text { penjualan kopi beras }\end{array}$ & Ya & $\mathrm{Ya}$ & Ya \\
\hline
\end{tabular}

Kriteria Mutu Kopi Arabika pada Beberapa Koperasi dan Eksportir di Aceh Tengah. (Abdul Kudus, Heru Prono Widayat, Yusya' Abubakar)

Jurnal Ilmiah Mahasiswa Pertanian. Vol. 4, No.2, Mei 2019: 274-279 
Penerimaan kopi arabika pada eksportir B yaitu petani melakukan pemanenan kopi gelondong dan menjual pada pengepul ataupun tengkulak. Pada tekkulak/pengepul melakukan peroses lagi yaitu penggilingan glondong dan penjemuran gabah. Setelah penjemuran selesai kopi gabah langsung di jual pada eksportir tetapi terlebih dahulu eksportir mengirim petugas ke tempat penjualan untuk penentuan harga. Setelah penentuan harga selesai kopi di bawa ke pabrik dan dilakukan penjemuran gabah kembali hingga kadar air 12\%. Lalu dilakukan penyortiran setelah itu kopi arabika gayo di masukkan dalam gudang.

Pada koperasi A yaitu petani melakukan pemanenan kopi gelondong dan menjual pada pengepul ataupun tengkulak. Setelah sampai di tengkulak ataupun pengepul, kopi di lakukan penggilingan gelondong dan sekaligus penjemuran kopi gabah. Setelah gabah kering, gabah langsung dijual kepada koperasi, dan petugas koperasi langsung melakukan pengecekan kadara air, triage, dan penampakan sekaligus menentukan harga kopi gabah. Selesai melakukan penentuan harga, kopi dibawa ke pabrik dan dilakukan penjemuran gabah lagi dan melakukan penggilingan kopi gabah hingga menjadi kopi biji kopi. Dan melakukan penyortitan kopi dan setelah selesai penyortiran kopi dilakukan cup test rasa sebelum penggudangan.

Pada koperasi B. Petani melakukan pemanenan kopi gelondong setelah kopi glondong di panen petani menjual pada tengkulak atau pengepul. Setelah sampai pada pengepul kopi gelondong dilakukan penggilingan gelondong dan penjemuran. Setelah penjemuran selesai kopi gabah langsung di jual kepada koperasi sekaligus penentuan harga. Kopi yang telah di tentukan harga langsung dibawa ke pabrik. Kopi yang sudah di pabrik langsung di jemur hingga kadar air yang diharapkan. Kopi gabah yang kering langsung di giling hingga menjadi kopi beras, dan dilakukan penyortiran setelah selesai kopi langsung di tester. Kopi yang sudah dilakukan semua tahap langsung di masukkan ke dalam gudang.

\section{KESIMPULAN DAN SARAN}

Kesimpulan yang didapat pada penelitian ini adalah kadar air kopi gabah yang dapat diterima oleh eksportir dan koperasi adalah maksimal sebesar 60\%. Koperasi dan eksportir melakukan proses yang lebih lanjut (seperti penerimaan dan sortir) agar mutunya sesuai dengan Standar SNI dan SCAA. Eksportir A, eksportir B dan juga koperasi A, koperasi B melakukan pengolahan lanjutan agar kopi yang sudah di beli dari petani/ pengepul sesuai dengan syarat mutu SNI dan SCAA. Perlunya dilakukan perbaikan manejemen pengolahan pada koperasi dan eksportir di Kabupaten Aceh Tengah hingga ahir demi peningkatan mutu kopi yang dihasilkan.

\section{DAFTAR PUSTAKA}

AEKI. 2013. Laporan Realisasi Ekspor Kopi Arabika Provinsi Aceh. Aceh (ID): AEKI.

AEKI.2011.Luas Areal dan Produksi. Diakses 12 Maret 2013.

Arpah, M. 1993. Pengawasan Mutu. Tarsito. Bandung. Anonymous.2012. Mengenal jenisjenis kopi.

International Coffee Organization (ICO). 2012. All Exporting Countries Total Production Crop Years.International Coffee Organization. England.

Surip, M.2008 Buku Panduan Budidaya dan Pengolahan kopi Arabika Gayo, Siregar, S.2012. Metode Penelitian Kuantitatif. Prenada Media Group. Jakarta

Kriteria Mutu Kopi Arabika pada Beberapa Koperasi dan Eksportir di Aceh Tengah. (Abdul Kudus, Heru Prono Widayat, Yusya' Abubakar)

Jurnal Ilmiah Mahasiswa Pertanian. Vol. 4, No.2, Mei 2019: 274-279 